\title{
EXPLORING NATURE OF WORK FAMILY CONFLICT: AN EXPLORATORY STUDY IN THE BANKING SECTOR
}

\author{
Kengatharan.N \\ Department of Human Resource Management, University of Jaffna \\ nkenga@gmail.com
}

\begin{abstract}
The work family literature demonstrates the great vitality and diversity of scholarship and it is an omnipresent factor in the study of contemporary organizations and society. This study was designed to diagnose the pervading nature of work family conflict in Sri Lanka. A total of fifteen respondents were purposively selected from a high status occupations viz., banking organisations and the experience survey was employed. The majority of the employees interviewed are in accord with existence of time based and strain based work family conflict in Sri Lanka. Nonetheless, as the third form of work family conflict-behaviour based work family conflict-in the vantage point of the majority of the employees opined that there was a flimsy of evidence to its existence. Most importantly, this study identified a new form of psychological based work family conflict and thus these novel insights unequivocally contribute to revamp the work family conflict literature. This study becomes a springboard for future research studies.
\end{abstract}

Keywords: High status occupation, Role theory, Work family conflict

\section{INTRODUCTION}

Work family conflict (WFC) focuses on the difficulties employees have in balancing their work and family responsibilities (Adams, King, \& King, 1996). Albeit voluminous research studies on work family interference have been carried out in Western cultures, no research has attempted to excel the concepts of work family conflict in Asian culture a rather researchers on same culture have just applied the developed concepts in different culture without any questions. Notwithstanding, there are bereft of research in collectivist culture and it has thus been decided to conduct an exploratory study in order to clarify existing nature of work family conflict in Sri Lankan context. It thus helps to ensure adequate understanding of the investigating phenomenon and to provide lend support to mother lode concept derived from reviewed literature extant in the past. The objective of this research was twofold: one was designed to diagnose the nature of work family conflict and for portraying; other one is for dimension testing. Therefore, this research would exert meaningful interpretation to 
crystallise the concept associated with literature.

\section{THEORETICAL} UNDERPINNING

The concept of work family conflict emanated from role theory developed five decades ago (Kahn et al., 1964). In this theory, work and family conceptualized as role systems and the role process is an interaction between role performer (focal person) and role sender. The "simultaneous occurrence of two (or more) sets of pressures such that compliance with one would make more difficult compliance with the other" (Kahn et al., 1964, p.19) creates role conflict. Thus in the case of WFC inter role conflict arises when pressures from the work role are incompatible with the pressures arising from the family role and vice versa.

Based on this deep rooted idea, the most widely accepted definition of work family conflict was postulated by Greenhaus and Beutell (1985) as "a form of inter role conflict in which the role pressures from the work and family domains are mutually incompatible in some respects" (p.77). Therefore, the inter role conflict occurs when participation in one role consumes more resources (e.g., working long hours), which is incompatible with performance of another role (say leaving less time available for performing family role). Across many disciplines, the term 'work family conflict' is interchangeably denoted as work home interference (e.g., Geurts et al., 2003), work family interference (e.g., Carlson, Kacmar, \& Williams, 2000), and work non work interference (e.g., Dikkers et al., 2005).

Greenhaus and Beutell's (1985) scholarship was revolutionary in bringing three forms of work family conflict to light: time-based conflict, strain-based conflict, and behaviour-based conflict. Time-based conflict occurs because "time spent on activities within one role generally cannot be devoted to activities within another role" (Greenhaus \& Beutell, 1985, p.77). It is the time interference on performing either work or family role, for example, working more than eight hours or working on more than five days might interfere with his/her ability to get things done at home. Time is therefore disproportionately spent on work related matters compared to family related matters. Strain-based conflict occurs when strain from one role makes it difficult to perform in another role. For example, anxiety and fatigue caused by strain from the work role might make it difficult to perform in a family role (Greenhaus \& Buetell, 1985, p.80). The third form of WFC defined by Greenhaus and Buetall (1985) is behaviour-based conflict, in which "specific patterns of inrole behaviors may be incompatible with expectations regarding behavior in another role" (p.81).

All these forms of WFC have been developed from studies carried out in nations with individualist cultures, predominantly in Europe, Latin America and North America. 
However, studies in collectivist cultures have been very few. More recently, Shaffer, Joplin and Hsu (2011) have identified 49 research papers carried out in collectivist cultural nations in Asia. However, those studies have shortcomings and failed to confirm the extant forms of work family conflict. Thus, this study extends beyond all studies carried out in nations with collectivist cultures by investigating the extant forms of bidirectional WFC using a sample from Sri Lanka. This raises the question:

RQ: Are the three forms of work family conflict developed from research in individualistic cultures extant in Sri Lanka?

\section{METHODS}

\subsection{Subjects and Sampling}

As the overall purpose is in tune with diagnosing extant nature of work family interference, the best exploratory choice is the experience survey inter alia secondary data analysis and case studies. Experience survey is about selecting respondents (interviewees) who are experiencing problem in execution of work and family responsibilities. Input from experience respondents would become rich source in revealing the phenomenon to be investigated. Therefore, the success of study entirely depends on selection of experience respondents where they are able to articulate on a particular subject being inquired.

Sample has been drawn from Sri Lankan banking organisation. Taxonomies of the banking organisation fell into Bank of Ceylon, People's Bank, National saving Bank, Commercial Bank and Seylan Bank. Each bank has many branches across many districts in Sri Lanka. A convenient sampling technique was used to select the banks (branches of the banking organisation) in compliance with the formal approval of the managers of the respective banks. Having had some discussion with a few employees, the potential respondents who experience work family conflict was purposively identified. Prior to the interview, consent for participating interview was obtained. Altogether, fifteen informants were selected for this study; made up with a total of two manager, five assistant managers, two senior assistant manager, executive manager, staff assistant, management trainees, multi duty assistant, bank assistant and cashier.

\subsection{Instruments}

Since work family conflict is well developed concepts in Western countries and limited studies evidence to Asian countries, researcher has employed semi structured interview that concur with intended purposes. Nonetheless, designed semistructure interview elicits extensive in depth answer to certain extent.

Semi-structured questions melded with open ended and closed ended questions. Open ended questions offered a better place to discuss interviewee's experience on concepts or themes inquiring. Interview questions were mainly explored to elucidate core theme of work family conflict 
including, number of hours spending work, childcare and eldercare, causes of work to family conflict and family to work conflict, experience of work family interference, nature of support in work and family and work family friendly policies. It was the main responsibility of the researcher to control and guide the interview rather deviating from concept being studied. All interviews were conducted in Tamil language and then transcribed and finally translated into English by researcher himself who is native speaker with significant knowledge of the context and confirmed the results by using backward translation technique.

\subsection{Mode of Analysis}

Thematic content analysis has been employed to analysis the transcripts. "A theme refers to a specific pattern found in the data in which one is interested" (Joffe \& Yardley, 2004, p.57). Based on the strong theoretical ideas, themes are brought to the data in coding and thus, the coding is to be said "Deductive coding". Nonetheless, the nature of the coding can be conjoined with "manifest" and "latent" content of data using NVivo 10. Dependability and validity of the data (leading questions and cumulative validation) were confirmed.

\subsection{Results and Discussion}

This study made up of fifteen key informants where nine of them were male and remaining six informants were female. They were unique informants per se emanated from varying age groups, types of banking organisations, position, experience, educational qualification, average monthly income and gender. The highest number of informants falls between 36-45 age group, followed by an equal (four) number of informants from 36-35 and over 45 age groups and 2 informants were from 18-25 years. Different nature of positions were observed among informants including: Manager, Executive Manager, Senior Assistant Manager, Assistant Manager, Staff Assistant, Management trainee, Bank Assistant, Cashier and Multi Duty Assistant, prevalent among different types of banking organizations and years of experience were between 3 years to 20 years.

\subsection{Time interference between work and family}

On the basis of informants enlightening, time consumption can apparently be split into family and work. In case of family, informants explained that they are expending time mostly in doing household chores, childcare and eldercare. In a similar vein, competing time demand reported needing for work domain is to accomplish their assigned tasks at work and work travelling. Spreading time between both domains have been coded and visualised with the help of NVivo, in figure 1 


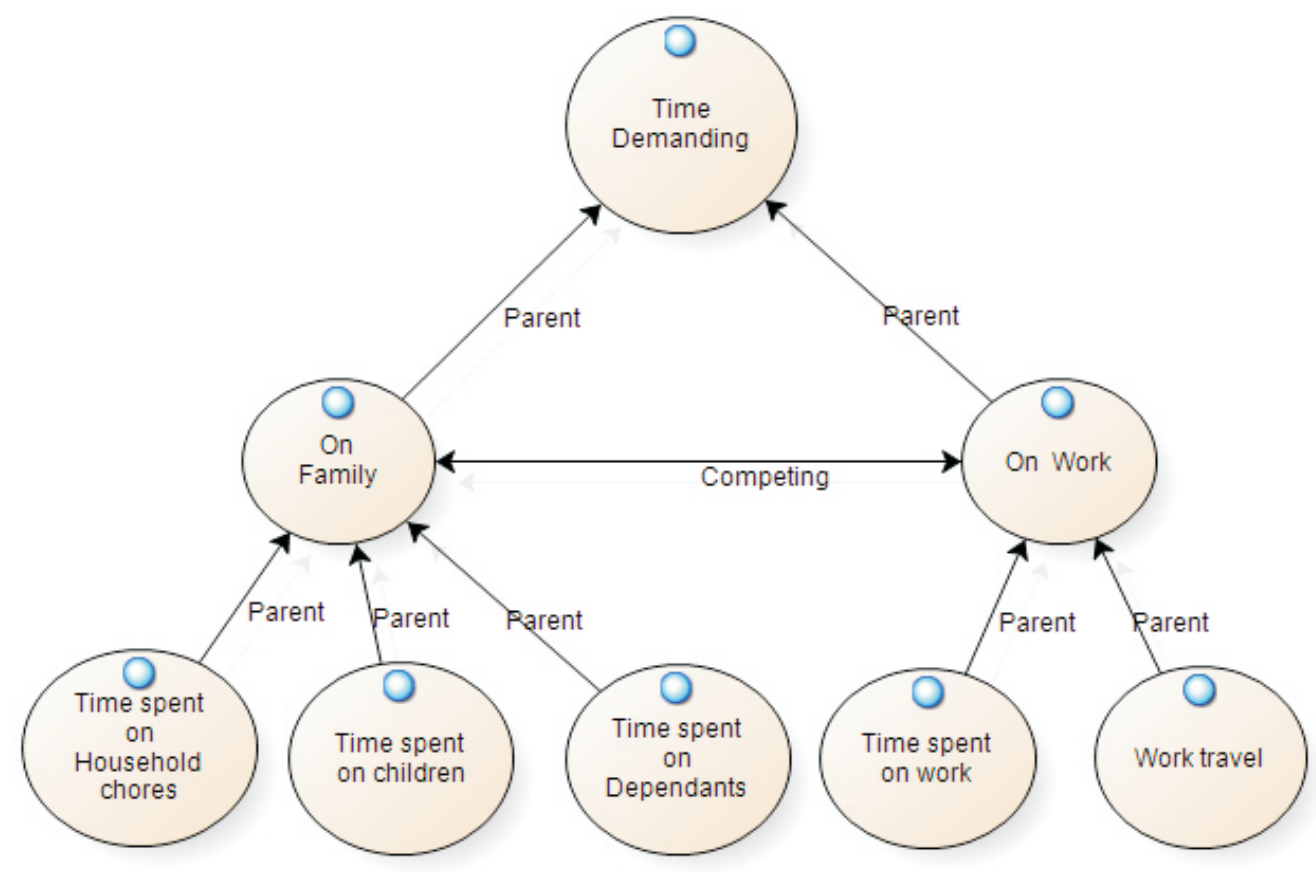

Figure 1: Time demand between family and Work

Time spend on family encompasses a wide range of family activities demarcated by family boundary per se. Family activities were grouped into time spend on household chores, childcare and eldercare. Informants had been asked how much of time they have spent on family between these three competing demand and also been inquired about their experience on performance of family role by virtue of participation in work role due to the time concerned.

Informants perform a wide variety of household chores in day to day life and a list of household chores culled from interview transcripts includes: Cooking, cleaning, teaching children, shopping, laundering, tiding up, washing, ironing, sweeping, taking children school, feeding pets, vehicle maintenance, watering plant, and gardening. Most of the informants expounded that the time spent on work inhibits doing household chores. Informants are working long hours, struggling to find time for spending with family and leaving most of the household chore needs doing today is for tomorrow. One of the key informants elucidated his view about how the matter of time interferences with household chores, the extracted verbatim quote is as

"I haven't got enough time for doing household chores, and for looking after children. Most of the tasks at home would 
usually be left or planning to do next day. It's common if both are working, everything doesn't look like the way it looks like to be. I feel I let my family down due to the long hours spent on work" (Interviewee 2)

One of the senior assistant manager explained how time spent on work interferences with household chores, quoted as

".....I have got too much responsibility at work. I work roughly 49 hours per week. I really understand it is too long hours but I need to be by job itself. So hunting time for doing household chores is like a wild goose chase. I hardly find time to do household chores because of many hours spent on work responsibilities. I ain't really supporting doing household chores........" (Interviewee 10)

Most of the informants were in discord with spending time by working overtime. One of the informants clearly expounded that overtime is not needed, but I need the time to spend with family and the verbatim quote is "I'm working full time and I usually leave my home at 8 am in mornings and I get back home nearly at $5.30 \mathrm{pm}$.I work on Saturdays as well...... It is much difficult to do all household chores every day. I need time to spend with family. I am oft-required to work overtime but actually I do not want to. My wife is also working. Our income is enough..." (Interviewee 7)

In overall, informants are struggling for doing household chores due to the time spend on work. In most of the cases, informants are compulsory required to work overtime regardless of their willingness.

Albeit extended family structure would support for childcare, parents are responsible for childcare. The time available for childcare with competing demand of work is challenging, needs to be balanced. Childcare is appropriate and needed for child who is too young to look after themselves. One of the another key informant cherished his memory in child caring, vignette of verbatim quote is

"I don't really have much time to spend with my son, however, he has grown up and old enough to look after himself. Time for childcare used to be big challenge when he was too little years ago..." (Interviewee 3)

The performance of the family responsibilities are more time sensitive, require many hours. Most of the informant said they have problems with finding time for doing tasks at work. It was noted the difficulties of doing all tasks at work in normal office hours. We needs to stay on bank after finishing working hours but family responsibilities are held them back. The nature of situation was explained by one 
of the informants as

"I've got too much responsibility at family.

..cleaning, shopping, taking children to school.. all tasks take more time. I am a senior assistant manager, I should also take more work responsibilities at bank, want to spend more hours, but I am really struggling due to family involvement." (Interviewee 9)

It can thus be said that time spent at family mutually interference with work. Informants expressed that they are facing lots of problem in doing tasks at work due to family involvement.

\section{Strain interference between work and family}

Another important dimension of work family interference is found to be related to strain nature. Strain based conflict is about the interferences in doing tasks at work due to the family involvement or in doing tasks at family due to the work participation. In this section, the wording "strain" "laziness" and "tiredness" were pervaded among verbatim quotes. All those terms inheres in strain based nature of conflict between work and family. One of the key informants unequivocally articulated how doing tasks at work interfere with tasks at family as:

"I am really got tired when I get home from work. It is difficult to do household chores straight away from work. I often feel I need a rest after coming home from work" (Interviewee 1)

In a similar vein, strain originated at family can also have impacted on the performance of work responsibilities. Employees often get tired and strained in consequence of family responsibilities. One of the informants clearly expressed her experience about how family responsibilities interference with work, supported by verbatim quote is as:

"I am really worn out when I get work from home. I do lots of household chores every day and getting my children ready for school. Family responsibilities interfere in doing work responsibilities. So I can't perform well on my job"(Interviewee 8)

In overall, most of the informants expatiate on strain based work family conflict and that evidenced to be originated from both work and family, found across many transcripts, view supported by several work family studies.

\section{Behaviour interference between work and family}

Third important dimension of work family interference is found to be related to behavioural nature. Based on the literature, behavioural nature in terms of problems solving pattern and different expectation of behaviour at home and work can be found to be causing conflict on mutually opposite 
domain. Notwithstanding, there was a flimsy evidence on this aspect of work and family interference among the informants. One of the informants said that nothing about the behavioural problem between both domains, verbatim quotes is as:

"I don't think there is a need for behavioural adjustment between work and home. We treat, be treated as family members in workplace. We work as team and have a complete openness among us" (Interviewee 12)

Another informant expounded that family behaviour in execution of family responsibilities does not seem to problematic penetration into work. She claimed that

"I don't think the way I behave at family affects the workplace. We are working together happily, we respect each other. You know the way I am speaking to is the way I behave at work and home" (Interviewee 11)

One of the key informant working as a multi duty assistant clearly refuted the behavioural nature of interference, and shared his view as

"I am at the lowest level in the bank. Almost everyone is my boss. I don't feel any behavioural issue in my experience. I observed the way we ask our children to get things done is virtually similar way supervisors ask me to do things.
Friendly life in both places, however, I know I need to be more serious at working place. Need to be completed given task in time" (Interviewee 14)

It was the options that the most of the interviewees interviewed that behavioural nature seemed to be less problematic in comparison with other dimensions. In summary, flimsy evidence has been found to be associated with behavioural based work family interferences. However, this concept further needs to be explored.

A seminal study of Greenhaus and Beutell (1985) brought to the three dimension of work family conflict: Time based work family conflict, strained based work family conflict and behavioural based work family conflict. Most of the work family interference factors were expounded by informants akin to what identified by those researchers in situ. More precisely, time spent on work, work load, long hours, too much responsibility, and overtime absorbed into time based work family conflict. In a similar vein, stress, tiredness and feeling of laziness, and work place pressure absorbed into strain based work family conflict. Behavioural based work family conflict factors have not been obviously elicited in all interviews, nonetheless, it can be supposed that work environment and culture might contribute to be beset such conflict. Notwithstanding, there was a conundrum about those remaining unidentified factors 
reflected in interview: long work travel, rows with colleagues and uneasiness at work, community involvement, engaging with social events, conflicts at work, thinking of work and work plan and worries at work. Of them, community involvement and engaging with social events were not directly or indirectly connected with work and family interference domains, and thus these factors have been noticed outside of work and family boundary and thence they treated as null and void. Long work travel has been recognised as partly related to work and partly to home. However, long hours travel is the factors taken place outside of the work and family domain. It is thus supposed to be treated as controlling factor of work family conflict. Remaining factors, viz., rows with colleagues and uneasiness at work, conflicts at work, thinking of work and work plan and worries at work seemed to be impetus for psychological related aspect. In 2003, Carlson and Frone proposed psychological aspects of work family nature in individualist country. In a similar vein, Spector, et al. (2007) connoted that there are unidentified factor influences in work family conflict in collectivist cultural nation. Therefore, in line with Carlson and Frone (2003) and Spector, et al. (2007), it can be presumed to be impetus for psychological related aspect.

\section{CONCLUSION}

There is sufficient evidence to lend support existence of work family conflict in explored area and incubate a viable plan for continuing extended research in this field. Majority of studies conducted in collectivistic cultures have applied and tested the concepts developed in individualistic culture without any questions. This exploratory is unique per se, designed to elicit employees' opinion about work family interference. This research was a great success, and informants clearly articulated their view about work family interference. Proposed dimension in a collectivist culture was also been refutably confirmed, thence to guide quantitative study encompassing large amount of sample which facilitate findings generalisation.

\section{REFERENCES}

Adams, G.A., King, L.A., \& King, D.W. (1996). Relationships of job and family involvement, family social support, and work-family conflict with job and life satisfaction. Journal of Applied Psychology, 81 (4), 411 420 .doi:org/10.1037/0021 9010.81.4.411

Carlson, D.S., \& Frone, M.R. (2003). Relation of behavioral and psychological involvement to a new four-factor conceptualization of workfamily interference. Journal of business and psychology, 17(4), 515535.doi: 10.1023/A:1023404302295

Carlson, D.S., Kacmar, K.M., \& Williams, L.J. (2000). Construction and Initial Validation of a Multidimensional Measure of WorkFamily Conflict. Journal of Vocational Behavior, 56(2), 
249-276.doi: $\underline{10.1006 / j v b e .1999 .1713}$

Dikkers, J.S.E, den Dulk, L., Geurts, S.A.E., \& Peper, B. (2005). Work-nonwork culture, utilization of worknonwork arrangements, and employee-related outcomes in two Dutch organizations', in Poelmans, S.A.Y., (ed.) Work and Family: An International Research Perspective. Mahwah, NJ: Lawrence Erlbaum Associates, 147-172.

Geurts, S.A.E., Kompier, M.A.J., Roxburgh, S., \& Houtman, I.L.D. (2003). Does workhome interference mediate the relationship between workload and well-being? Journal of Vocational Behavior, 63(3), 532-559.doi: 10.1016/S0001-8791(02)00025-8

Greenhaus, J.H., \& Beutell, N.J. (1985). Sources of conflict between work and family roles. Academy of management review, 10(1), 76-88. doi: 10.5465/AMR.1985.4277352

Joffe, H., \& Yardley,L. (2004). Content and thematic analysis in Marks, D.F. and Yardley,L. (ed.) Research methods for clinical and health psychology, Marks, D.F. and Yardley,L. London: Sage publication Ltd, 56-68.

Kahn, R.L., Wolfe, D.N., Quinn, R.P., Snoek, J.D., \& Rosenthal, D.A. (1964). Organizational stress: Studies in role conflict and ambiguity. New York: John Wiley.

Shaffer, M.A., Joplin, J.R., \& Hsu, Y.S. (2011). Expanding the boundaries of work-family research: A review and agenda for future research.
International Journal of Cross Cultural Management, 11(2), 221-268.doi: $\underline{10.1177 / 1470595811398800}$

Spector, P.E., Allen, T.D., Poelmans, S.A.Y., Lapierre, L.M., Cooper, C.L., O'Driscoll, M., Sanchez, J.I., Abarca, N., Alexandrova, M., Beham, B., Brough, P., Ferreiro, P. Fraile, G., Qin lu, C., Lu, L., Vela' Zquez, I.M., Pagon, M., Pitariu, H., Salamatov, V., Shima, S., Simoni, A.S., Siu, O., \& Widerszalbazyl, M. (2007). Cross-national differences in relationships of work demands, job satisfaction and turnover intentions with work-family conflict. Personnel Psychology, 60(4), 805-835. d o i : $\quad 10.1111 / \mathrm{j} .1744$ $\underline{6570.2007 .00092 . x}$ 